\title{
Some Ideas of Improving the Quality of Classroom Teaching for Engineering College Students
}

\author{
$\mathrm{Xu}$ shuqiong* and Li yunfang \\ College of Mechanical Engineering, Linyi University, \\ Linyi, Shandong 276005, China \\ E-mail: xushuqiong11@sina.com \\ * Corresponding Author
}

\begin{abstract}
How to improve the quality of classroom teaching and attract students' attention to the class are the problems that are thought by engineering college teacher. Some ideas of improving the quality of classroom teaching for engineering college students are presented in this paper. The ideas make the students feel that the class is interesting and useful, and gained a great deal from the class: Humanities education must be arranged in professional teaching; to implement heuristic teaching and interesting teaching method; to introduce combined with typical practical cases and catastrophic accident, to cultivate the awareness and ability of innovative design in the teaching process.

Keywords-quality; humanities education; heuristic teaching; interesting teaching; innovative design
\end{abstract}

\section{INTRODUCTION}

It is investigated that 30 percent of engineering college students like playing smart phone in the class and they pay no attention to the teacher. In this situation, How to improve the quality of classroom teaching and attract students' attention to the class are the problems that are thought by engineering college teacher. Some ideas of improving quality of classroom teaching for engineering college students are presented in this paper.The ideas make the students feel that the class is interesting and useful, they has gained a great deal from class.

\section{HUMANITIES EDUCATION MUST BE ARRANGED IN PROFESSIONAL TEACHING}

A lot of Challenges that engineers are faced stem from the non-engineering factors. Humanity education is an important part in engineering education, it shows the value-orientation in specialty teaching. Humanity factors have permeated into knowledge transmitting, ability training, and consciousness developing in the process of specialty teaching of engineering.

There are a large number of the history of science and technology in professional courses, which can be used to cultivate students' patriotism. The deeds of specific outstanding scientists who dedicated to the truth can stimulate the students' sense of justice and social responsibility; the history of science and technology uncovered the hard exploration process of scientists, it is the side of humanism. Through the solution of scientists who analyzed problems and solved problems, it can gradually cultivate the scientific spirit of the students, and courage them to explore and solve engineering roadblock, not afraid of setbacks, these can help students carry out dialectical materialism education, improve the students' scientific quality, develop scientific research ability and scientific attitude.

In the innovation activities Generations of engineers had accumulated abundant experience and knowledge of epistemology and methodology for us, which provide us with a demonstration guide for innovation. The history of science and technology can cultivate students' query spirit, thoughts of innovation and the sense of seeking change; students will have the ability of appreciating, reflecting an $\mathrm{d}$ creating beauty gradually in the appreciation of history of technology, we all know that pursuiting beauty can enrich the meaning of life and improve the quality of life. [1-4]

Every student in the university is the only one who needs the teachers to find, to appreciate and to polish.

We think that the humanities education should be implemented in engineering courses, we did a try in the engineering materials and materials mechanics .Teaching professional courses is not only to teach professional knowledge, but also more important thing is to make students feel through learning professional knowledge, improve thinking ability and sublimate the state of the spirit of the students. Each material has advantages and disadvantages, it has been used by the different performance. No one is perfect, each student has his own advantages and disadvantages, to play their strengths, each of them is a talent. In teaching, we teach student that the world is different because of my existence, the world is more beautiful because of my existence, and I am truly useful, this Make the students feel that they are full of positive energy.

Here are some of the works we have done in engineering materials the course. According to the contents, the law of contradiction in the evolution of material properties is described, the dialectical law of the effects of alloy elements is summarized, the law of quantitative and qualitative change of materials microstructure evolution is revealed. We let the students know that the truth is relative, if the conditions are changed, the conclusion may be changed. Fine grain steel is not the smaller the grain size, the higher the strength and hardness, mechanical properties are the best when the grain is $4 \sim 5 \mu \mathrm{m}$. The grain is too thin at high temperature is not good. Hooke's law in certain conditions is established; body centered or apical positions of atoms at the body centered cubic lattice, for different cell selection it can be located on the vertex or the center of the unit cell. 
We teach students how to research problems dialectically and comprehensively. Metallurgical structure examination the material microstructure of the within the organization of the authenticity of the problem, In fact, what we see is just a local organization, Therefore, it is should be emphasized that the key parts of the materials must be cut out so as to research scientifically. Seeing is not real. Another example is that the cold hardening, stress concentration, texture, residual stress and so on has its advantages and disadvantages; we explain the definition of crystal with dialectical materialism epistemology to let students understand the limitations of the traditional crystal definition, the found of quasicrystal enhanced and extended the connotation of the crystal. Innovative teaching methods make students understand and grasp the connotation of curriculum, and cultivate students' ability of analyzing and solving problems, and to inspire innovative thinking.

\section{TO IMPLEMENT HEURISTIC TEACHING AND INTERESTING TEACHING METHOD}

Learn started from think, and think come from doubt. The Design and implement of the heuristic teaching method in the whole teaching process, and careful design and assignment of reflection questions in each class will make the students to think. Thought will reward, and think constantly there must be repercussions. Learning is not a simple accumulation of knowledge, but a systematic integration of knowledge points. It should emphasize on knowledge points in the course of lesson and highlight the study system and ideas on a stage or final summary, such as the effects and mechanism of the each alloy elements, dialectical relations of the effect of alloying elements and technics on strengthening and toughening. Such reaching method has excellent teaching effect that the students not only learn the knowledge of the course, but also grasp and understand the connotation of the material, which achieves the purpose of lively learning to and well learning.

"Interest is the best teacher", which plays an important role in stimulating learning motivation and arousing the enthusiasm of students. Once the learning interest is stimulated, it can arouse the infinite spirit of exploration and the desire for knowledge. Course group of "Engineering Materials Science" in the teaching process has used the interesting teaching actively and achieved satisfying teaching results. In practical teaching, we consider to introduce the introduction to cultivate the students with the sense of mystery, excitement and accomplishment about the course, and improve the curiosity of the student about the curriculum. The introduction of references, historical sources, the edutainment and the introduction of typical examples into life can inspire the interest of study. In practice teaching, in order to let the students understand the steel strength, stiffness, plastic, toughness and brittleness and other abstract concepts, we choose a animation of "five ball fell to the ground", in which the spheres are bright colored and land effect of spheres is different. Then combined with examples, students can easily understand the different of material properties and the behavior in macro scope. The properties of iron carbon steel are change along with the variation of the carbon content. In addition, with the help of the stamping image of steel plate on the spot and the animation from software simulation about the stamping process of steel plate and the grain deformation to explain relevant theory about the plastic deformation. For the concept of dislocation that students are more difficult to understand, we can use the animation and the movement of Inchworm to assist teaching, which are lively and interesting. Such micro and macro contact are also often used on the analogy about microstructure and macroscopic natural things. For example, some organizations are like different kinds of branches, various blooming chrysanthemums, while some organizations are similar with feathers, bamboo leaf and island shape, other organizations resemble with stars at the black sky, ribbonlike river, fishbone or dry cracked land. Using vivid language to alive the dead tissue can not only active the classroom atmosphere causing the study interest of students, but also let the students to feel the micro beauty of the world and make study to receive beauty education to left a deep impression to the students. In the teaching, it should to introduce the related famous story appropriately, which can inspire students to better understand the complex knowledge. The cognitive process of students on related scientists can improve the learning interest and efficiency, promote the in-depth understanding of specialist knowledge, and promote the formation of professional innovative thinking. Teachers should try to put the old and advanced knowledge as lively as fresh fish so that making each lesson becomes the most exciting lesson.

\section{TO INTRODUCE COMBINED WITH TYPICAL PRACTICAL CASES AND CATASTROPHIC ACCIDENT, RECEIVING EXCELLENT TEACHING EFFECT}

Combined with the video to explain the practical case and catastrophic accidents to bring a strong impact on visual and psychological of students, and make students really appreciate the importance of materials, Such as the sinking of the Titanic, which was found in the Atlantic sea in the seventy or eighty of the last century. People obverted that the microstructure of the rivets has lot of inclusions, indicating the materials have problem. In the hypothermic sea-water, the rivet fracture leads the water into the six sealing tank, which cause the sinking of the Titanic. The chemical composition analysis result of hull steel are shown in TABLE 1. Lock Gate is the shipbuilding steel of the United States in 1912, ASTM A36 is the modern Hull Steel. We can see that the percentage composition of $\mathrm{S}$ is very high in Titanic hull steel, while the Mn content is low, so that the steel Mn:S ratio is only $6.8: 1$, far below the modern standard $15: 1$.

TABLE 1. The chemical composition analysis result of hull steel (\%)

\begin{tabular}{llllll}
\hline Hull Steel & $\mathrm{C}$ & $\mathrm{Mn}$ & $\mathrm{P}$ & $\mathrm{S}$ & $\begin{array}{l}\text { Mn:S } \\
\text { Ratio }\end{array}$ \\
\hline $\begin{array}{l}\text { Titanic } \\
\text { Hull Plate }\end{array}$ & 0.21 & 0.47 & 0.045 & 0.069 & $6.8: 1$ \\
\hline Lock Gate & 0.25 & 0.52 & 0.01 & 0.03 & $17.3: 1$ \\
\hline $\begin{array}{l}\text { ASTM } \\
\text { A36 }\end{array}$ & 0.20 & 0.55 & 0.012 & 0.037 & $14.9: 1$ \\
\hline
\end{tabular}


The other example is the crash of Challenger space shuttle. In January 28, 1986, the Challenger space shuttle of United States disintegrated and explodes into thousands of pieces after blastoff about 73 seconds, because of the failure of the right side of the solid rocket thruster above an O-shaped ring. The third example is the derailment accident of high-speed train in German. In June 3, 1998, a high-speed train derailment occurred in Eechede, Germany, which kills 100 people and injures 88 others. The analysis shows that the accident is caused by the metal fatigue of vehicle tyre that results in the suddenly break of wheel tyre. [5-8]

In the introduction of the importance of material mechanical properties, we import the typical case of the evolution of the rod material. In the impact of the progress of science and technology on sport performance, the evolution of the pole vault can be said to be a classic example. Its development process shows us the process completely that a new material makes the oldest sports to the pinnacle. In the movement of the pole vault, the improvement of pole material has experienced five stages: wood, bamboo pole, metal rod, glass fiber rod and carbon fiber rod. Pole vaulting results in wood stage is only 3.30 meters. In 1905, a bamboo pole can jump to 4.77 meters and in 1930, with a metal rod can up to 4.80 meters. But the real breakthrough is in 1985, Soviet athletes Bubka, who is known as "pole vault tsar", makes a jump exceeded 6 meters with aid of a modern pole fabricated by the mixture of glass fiber, synthetic resin and super soft, super strength fiber. He maintained a 21 year pole vault of man outdoor record, which is 6.14 meters and no one has broken today. In his opinion, to improve athletic performance, new materials must be developed for pole. The evolution of the pole vault world record with the development of pole material is shown in Fig .1. [9]

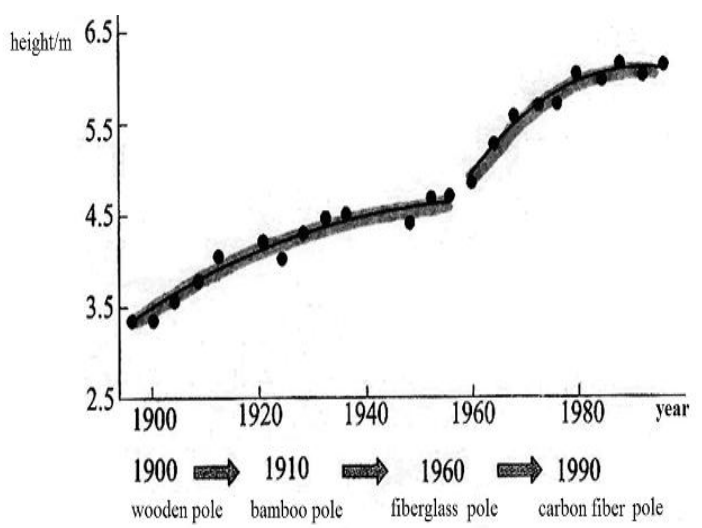

Figure 1.The evolution of the pole vault world record with the development of pole material

\section{TO CULTIVATE THE AWARENESS AND ABILITY OF INNOVATIVE DESIGN IN THE TEACHING PROCESS}

The innovative design method is a practical activity which uses the related science and technology knowledge, carries on the innovation idea and designs, the product which has novelty, creativity and practicality. Innovative design emphasizes creativity, puts forward a new plan, and provides a new and unique design. Teachers should introduce the famous cases which are designed by using innovative design methods. These cases give students a profound impression and great inspiration, these teach people to fish and play important role of training students' innovative consciousness and innovative ability.

Let 's have a research on the following sample, the traditional and innovative design case of French fries: when it is designed with conventional design:

cleaning - peeling - cut - slice

The shortcomings of this design need cleaning, peeling and cutting equipments, and due to variation shape and size of the potato, peeling thickness is difficult to be controlled, resulting in serious waste of potato and the productivity is low.

when it is designed with innovative ideas, the results are very different:

cleaning-crushing-filter, peel-precipitation, pulpingstrips made by pressure plate

The design improves the productivity, reduces the consumption, and reduces the cost of the machine. It is obvious that the performance of the product is the best by using innovative design. [10]

Let's study another famous engineering innovation case. PLA University of Science and Technology use the principle of the pressure bar instability to achieve "soft landing" of the high bridge blasting and completed an important project innovation. the pier concrete was shattered by single blasting, and reinforcement cages were only left, then the reinforcement cages lose stability under pressure, spindle shape was formed in the middle; it was flattened by gravity instantly, the bridge landed safely and achieved "soft landing". The blasting experiment of bridge pier is shown in Fig .2. [11]

Innovative cases should be introduced to the students in classroom teaching, the mechanical innovative design courses must be opened, the teacher implement innovative education combined with innovative practice, these are effective means to improve the innovation ability of college students in mechanical engineering.

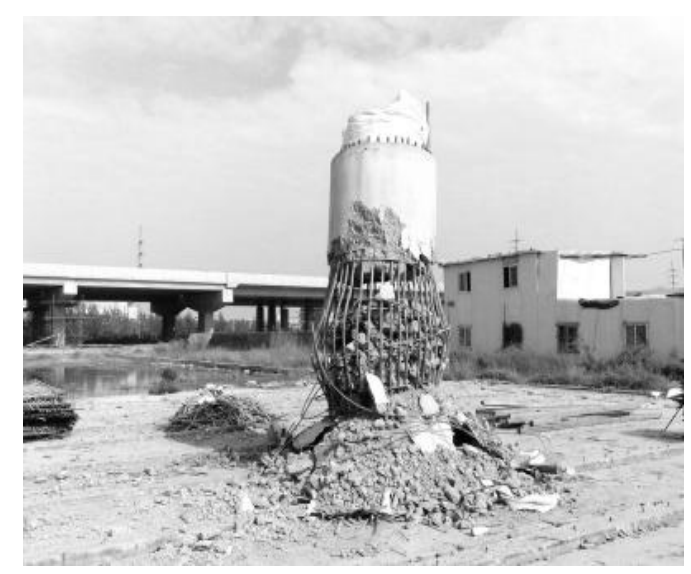

Figure 2. The blasting experiment of bridge pier

Experiments are another good way that can help to develop the ability of integration of theory and practice, to improve the ability of solving the practical problems independently, then it can improve the ability of innovation.The traditional experimental teaching mode has the following problems: the experiment focuses 
on proving the theory of books, students can not explore the unknown, research and development; programs and steps are determined by the guide books, so the creative ability of students was restricted. These problems could not bring full play of the creativeness and initiative to participate the experiment, objectively, which has made the students neglect the experiment and take the theory seriously. The experiment is only a teaching subsidiary and students generally do not attach importance to the experiment, the student's test performance can not reflect the student's ability and level of practice.

In order to solve the above problems, comprehensive and design experiments should be set up after completion of the required basic experiments. The comprehensive and design experiments can help the students to make the integration of theory and practice. In the process of completing of the comprehensive experiment, by the design, operation and exploration of the experiments, the students deepen to understand the theory and concept of textbooks, the students' creative and practical quality are strengthened from the combining of the abstract theory with practice.

According to the comprehensive experimental report to carry out the evaluation of the experiment, We had put forward performance evaluation criteria of the experiment. Including excellent, good, medium, pass, fail five grades. The following is the evaluation standard of the experiment for engineering materials course. If it meets the following conditions, the experimental evaluation is excellent. Students can apply learned theoretical knowledge, with references of the relevant literature, under the given conditions, selection of materials is reasonable, a reasonable heat treatment process can be worked out, the selection of equipment is also reasonable; the student has strong ability of operating independently in implementation of the process, the whole process of the experiment can be well done, the obtained results are reasonable and correct; comprehensive experimental report is clear and coherent, with clear diagrams, neat writing; the comprehensive analysis of the heat treatment process and the experimental results are shown in the report, and the student has a certain independent opinion on the experiment, the performance evaluation can be rated as excellent. If the student' learning attitude is not serious, often absent. The learned theoretical knowledge can not be used to select the materials and design the heat treatment process, experimental operation ability is poor, unable to complete the experiment task; comprehensive experiment report is not serious, there are not results on the experiment, it can be rated as failure. [12]

\section{CONCLUSIONS}

The teachers of engineering college must take fostering integrity and promoting rounded development of student as the fundamental task of education, and provide well-rounded education for student, focus on improving the quality of classroom teaching, and cultivate in students a spirit of innovation.

\section{ACKNOWLEDGMENT}

This work is supported by the National Natural Science Foundation of China (Grant No. 51302126), the Natural Science Foundation of Shandong Province, China (Nos. ZR2013EMM001 and ZR2013AL008) and the Startup Foundation for Doctoral Research of Linyi University, Shandong Province, China (No. LYDX2013BS004).

\section{REFERENCES}

[1] L.X.J. Humanity Education in Specialty Teaching of Engineering. Huazhong University of Science and Technology press, 2003.

[2] M.G,X.X.L. Quality education function of Chemical History. Journal of Chemical Education. 2010(04).

[3] D.Q.X. Metal Materials Science (2nd Edition). Chemical Industry Press, 2012

[4] The Research Group, School of Education in Huazhong University of Science and Technology. C.M, B.Y.X. Humanity Education in Specialty Teaching of Engineering. Research in Higher Education of Engineering, vol.3, pp. 29-34, 2008.

[5] http://www.kepu.net.cn/kepukongjian/imr/imr_word/201412/t2014 1217_8275.html:Talking about materials failure

[6] http://www.scitech-youth.org.cn/club_jz/lyy_20120610/

[7] L.Y.Y. The materials problem of the space shuttle disaster and the sinking of the Titanic

[8] ZH.Y.T, L. Y.Y. Columbia tragedy and materials. Science \& Technology Review. 2005(07).

[9] ZH.Z.Z. The light of science and technology in the Olympic Games. Higher Education Press.2008.

[10] ZH.C.L. Mechanical Innovative Design (2nd Edition). China Machine Press, 2007.

[11] http://www.yangtse.com/system/2012/02/14/012705633_01.shtml

[12] Z.M.Q, C.L. Teaching reform and practice of comprehensive experimental course of mechanical engineering materials. Journal of Peking University(Philosophy and Social Sciences), 2007(S2) 